\section{WELLBEING AT WORK; A EUROPEAN PEROSH PERSPECTIVE AND WELLBEING TREE}

${ }^{1}$ David Fishwick*, ${ }^{1}$ Edward Robinson, ${ }^{2}$ Noortje Wiezer, ${ }^{3}$ Zofia Mockallo, ${ }^{4}$ Vincent Grosjean, ${ }^{5}$ Lars L Andersen. ' Centre for Workplace Health, HSE, Buxton, Derbyshire, UK; ${ }^{2} T N O$, Leiden, Netherlands; ${ }^{3}$ IOOP-PIB, Warsaw, Poland; ${ }^{4}$ Working Life Department, INRS, France; ${ }^{5}$ National Research Centre for the Working Environment, Copenhagen, Denmark

\subsection{6/oemed-2018-ICOHabstracts. 1651}

Introduction PEROSH stands for the Partnership for European Research in Occupational Safety and Health. One of the joint research projects run from the PEROSH network deals with Wellbeing at Work, within which scientific representatives from five European countries have developed a set of initiatives aimed at improving working lives.

Methods In order to allow employers and workers to better understand the determinants of wellbeing at work, a model of wellbeing at work was developed, based on scientific knowledge, in three meetings which experts from different fields attended.

Results The WellbeingTree was developed as both a visually attractive and interactive graphic, but also to allow better understanding of wellbeing issues, and their determinants, at work. The tree incorporates abstracts, studies and case studies gathered from the international Wellbeing at Work conferences, but also relies on literature reviews and original articles. The symbol of a tree was adopted because effects of optimising worker wellbeing can be represented as the tree's fruits, and the roots of the tree were designed to represent the precursors, or antecedents, of wellbeing. The roots and branches thus give the user of the tree an opportunity to appreciate the wide variety of influences that may positively, or indeed negatively, influence wellbeing. A variety of sources of feedback about its usefulness have been received, and work is ongoing within PEROSH to develop these further.

Discussion We are now developing the tree further graphically, and it will be populated over time with references to scientific studies and cases. An interactive, 'clickable' version will be developed for use by employers, where clicking on a particular area of the tree will display relevant content. Our European approach to worker wellbeing has successfully developed a tool that we believe will be a useful resource for all those with responsibility for wellbeing of workers.

\section{SECTORAL DIFFERENCES IN WORKPLACE ILL- TREATMENT IN IRELAND}

${ }^{1} \mathrm{~V}$ Hogan*, ${ }^{1} \mathrm{M}$ Hodgins, ${ }^{1} \mathrm{~L}$ Pursell, ${ }^{2} \mathrm{~S}$ McCurtain, ${ }^{3} \mathrm{P}$ Mannix-McNamara, ${ }^{4} \mathrm{D}$ Lewis. ${ }^{1}$ School of Health Sciences, NUI Galway, Galway, Ireland; '2Kemmy Business School, University of Limerick, Limerick, Ireland; ${ }^{3}$ School of Education, University of Limerick, Limerick, Ireland; ${ }^{4}$ Plymouth Business School, Plymouth University, Plymouth, UK

\subsection{6/oemed-2018-ICOHabstracts. 1652}

Introduction It is well known that bullying varies by sector (Fervre, et al., 2012). However, national Irish data on workplace bullying and mistreatment in the workplace predates the economic recession, therefore, may no longer reflect current trends in Ireland. Therefore, this study aimed to establish the prevalence of workplace mistreatment in a nationally representative sample of Irish employees and to examine sectoral patterns in order to identify higher risk sectors.

Methods The data for this study comes from the first Irish Workplace Behaviour Study (IWBS), which replicated the
British Workplace Behaviour Survey conducted in 2008 (BWBS) (Fervre, Lewis, Robinson \& Jones, 2011). This Irish study consisted of a cross-sectional study of a national probability sample of employees. Survey data was collected through the use of an Omnibus Survey of the Irish population. The sample consisted of 1764 people aged 18 and over. A response rate of $74 \%$ was achieved. Data analysis was conducted using SPSS Version 22.

Result Ill-treatment across sectors were compared using a three factor structure comprised of unreasonable management, incivility and disrespect and the experience of violence or injury. In addition, the prevalence of experience, witnessing and perpetration of mistreatment across sectors is presented. The public sector and large organisations are identified as higher risk sectors within Ireland.

Discussion Prevalence rates of workplace ill-treatment are examined with reference to both national and international comparative findings. Sectoral differences in prevalence rates of workplace mistreatment indicate increased risk for certain working populations and have implications for the management of mental health and well-being.

\section{3 'RESILIENCE PLUS': PROMOTING SELF CARE \& WELLBEING BY CONNECTING WITH OURSELVES, EACH OTHER AND OUR WORK}

${ }^{1,2,3} \mathrm{~K}$ Costelloe*, ${ }^{4} \mathrm{~B}$ Lynch, ${ }^{4} \mathrm{~J}$ Wilson O'Raghallaigh, ${ }^{4} \mathrm{~J}$ Lavelle. ${ }^{1}$ Head of Learning and Development, RGN, MSC, PGDip, Beaumont Hospital, Dublin, Ireland; ${ }^{2}$ Counselling Services Manager, MSc Mindfulness Based Interventions, Beaumont Hospital, Dublin, Ireland; ${ }^{3} \mathrm{Dr}$. Principal Clinical Psychologist, Beaumont Hospital, Dublin, Ireland; ${ }^{4}$ MSC Candidate Psychology, Trinity College, Dublin, Ireland

\subsection{6/oemed-2018-ICOHabstracts. 1653}

Introduction The objective of Resilience Plus was to design, test, implement and evaluate an intervention to support health care employee wellbeing. A positive and supportive work environment is associated with reduced hospitalisation and costs, increased effectiveness and innovation, increased well-being, improved multi-disciplinary team delivered patient care, lower patient mortality, reduced error rates, reduced turnover and reduced sickness absence.

Methods Following a learning needs analysis and informed by clinical experience the programme was co - designed to combine direct learning, peer support and home practice over nine weeks. Staff across mixed disciplines and grades come together to share experiences and learning in a supportive, non-judgemental environment. Three quantitative questionnaires were selected to collect data: General Health Questionnaire (GHO - 12), Schutte Self-Report Emotional Intelligence Test (SSEIT) and Connor-Davidson Resilience Scale. Measures are completed prior to programme, at week 9 and 6 months post completion.

Results More than 130 employees attended the training programme during 2015/16, with 99\% of participants completing the programme. ANOVA testing determined there were statistically significant differences pre and post on the ConnorDavidson Resilience Scale ( $F$ 91.73, 46.82)=6.16, $\mathrm{p}<0.01$ ), the Schutte Self Report $(1.69,45.69)=15.96, \mathrm{p}<0.00)$ and the GHQ $(F(1.51,40.74)=8.50, \mathrm{p}<0.00)$. These improvements were maintained at 6 month follow up, which suggests the effects of the programme are maintained.

Discussion Resilience Plus is contributing to autonomous selfcare and improvements in general health and wellbeing 
amongst employees in a large acute Hospital setting. The diversity of programme attendees is contributing to shared learning and networking across boundaries. By tapping into internal expertise and developing internal capacity to deliver the programme we have created a cost effective, sustainable model that is directly transferable to the wider health care setting.

\section{\begin{tabular}{|l|l}
\hline 474 & PROJECT HAPPINESS AND WELLBEING FOR INDIANOIL
\end{tabular}}

Sandeep Sharma*, SK Awasthi. Indian Oil Corporation Ltd, New Delhi, India

\subsection{6/oemed-2018-ICOHabstracts. 1654}

Introduction The measures for enhancing 'Wellbeing' are complement to HSE measures to make sure that all workers are safe, healthy, contended and are effectively engaged at work. In fact, Happiness and Wellbeing of the workforce is a key factor in any organisation's long-term effectiveness.

Materials and methods IndianOil Corporation has taken Happiness for their employees as a project and under this Project weekly questionnaire were started along with small reading material on various parameters which are the factors controlling our state of mind and ultimately effecting the one's Happiness and Overall Well Being, Mental Attitude and Outlook, Time Management, Recognising and Managing Common Thinking Errors, Personal Wellbeing, Self Esteem and Self Confidence, Relationships for Health and Happiness, Positive and Negative Emotions, Burnout Factors in Your Work life, Health Fitness and Healthy Habits, Anger Management, Your Communication Style, Positive attitude and Gratitude. Project on 'Happiness and wellbeing' in IndianOil focuses on the psychological aspects of a fulfilling and flourishing life and provides practical guidelines to enhance Happiness and Wellbeing. IndianOil also launched a book prepared by Corporate HSE on 'Happiness and Wellbeing.

Result In response to the weekly questionnaire on Happiness and Wellbeing, we received an overwhelming response and willingness from employees to join the Project Happiness and Well Being, which helped IndianOil employees to understand fundamental issues in happiness and well-being, thereby making their official and personal life more meaningful, safe and effective. This program provides an insight into their mindsets and mental models that underlie their everyday behaviour and experience of life.

Discussion Project Happiness and Wellbeing brought more happiness in our management style, Smile and look happy when you are at work, cultivate optimism; convey calm and faith in the future, in this way we create a much more efficient and adaptable organisation.

\section{ESTIMATING THE NUMBER OF OPIATE OVERDOSES RELATED TO OCCUPATIONAL INJURIES IN THE UNITED STATES, 2011-2015}

\footnotetext{
1,2Devan Hawkins*, ${ }^{1}$ Kevin Schott, ${ }^{3}$ Patricia MacCulloch, 'Laura Punnett, 'David Kriebel. ${ }^{1}$ Department of Public Health, University of Massachusetts Lowell, Massachusetts, USA; ${ }^{2}$ Massachusetts Department of Public Health, Boston, Massachusetts, USA; ${ }^{3}$ School of Nursing, University of Massachusetts Lowell, Lowell, Massachusetts, USA
}

\subsection{6/oemed-2018-ICOHabstracts. 1655}

Introduction The incidence of fatal opiate overdose in the United States has drastically increased over the past two decades, resulting in significant attention from the public health and medical communities. Intervention efforts to reduce overdose mortality have primarily focused on regulating prescriptive practices and the dissemination of naloxone with less focus given to primary prevention. Preventing occupational injuries is one area where primary prevention is possible. In order to understand the potential impact of such prevention, this study sought to estimate the number of U.S. opiate overdose deaths from 2011 through 2015 attributable to occupational injuries.

Methods The number of reported occupational injuries occurring in the United States was obtained from the U.S. Bureau of Labour Statistics' Survey of Occupational Injuries and Illnesses from 2011 to 2015. A literature review was conducted to obtain estimates of the probability of being prescribed an opiate after any occupational injury, the probability of being prescribed an opiate after a low back injury, and the probability of overdose mortality following an opiate prescription. These estimates were then combined to obtain an estimate of how many opiate overdose deaths would be expected for the numbers of occupational injuries recorded in 2011-2015. Monte Carlo simulations were used to model the uncertainty in these estimates.

Results It was estimated that 718 (95\% Confidence Interval: 667 to 775$)$ opiate overdose deaths attributable to all occupational injuries occurred from 2011 to 2015. This risk of mortality was estimated to be $30 \%$ higher for the sub-group with low back injuries.

Conclusion The primary prevention of occupational injury holds great promise to reduce the devastating personal and economic impact of opiate overdoses. Further research is recommended to provide additional evidence highlighting the pathway from various types of occupational injury to opiate overdoses.

\section{HEALTHY ENTERPRISE STANDARD (HES) EVALUATION: IMPACT ON LIFESTYLE HABITS AND SELF-RATED HEALTH}

${ }^{1,2} \mathrm{D}$ Bellemare*, ${ }^{2} \mathrm{C}$ Duchaine, ${ }^{3} \mathrm{M}$ Vézina, ${ }^{3} \mathrm{M}-\mathrm{M}$ Mantha-Bélisle, ${ }^{4} \mathrm{H}$ Sultan-Tä̈eb, ${ }^{5} \mathrm{~F}$ StHilaire, ${ }^{1,2} \mathrm{C}$ Brisson. ${ }^{1}$ Faculty of Medicine, Laval University, Quebec City, Canada; ${ }^{2} \mathrm{CHU}$ de Québec Research Centre, Population Health and Optimal Health Practices Unit, Quebec City, Canada; ${ }^{3}$ Institut national de santé publique du Québec (INSPQ), Quebec City, Canada; ${ }^{4}$ Université du Québec à Montréal, Montreal, Canada; ${ }^{5}$ Management School, University of Sherbrooke, Sherbrooke, Canada

\subsection{6/oemed-2018-ICOHabstracts. 1656}

Introduction A significant portion of the burden of illness of workers in Canada and the United States is attributable to poor lifestyle habits, namely smoking, physical inactivity and low consumption of fruits and vegetables. The Healthy Enterprise Standard (HES) targets four intervention areas, including one to promote healthy lifestyle habits. The aim of this study was to evaluate the impact of HES implementation on workers' smoking behaviour, physical activity, consumption of fruits and vegetables as well as their self-rated health status.

Methods This was an intervention study with a before-after design derived from secondary data. Organisations adopted the standard of their own initiative and were responsible for implementing interventions. All active employees of ten Quebec organisations were solicited to participate before $(\mathrm{T} 1=2849)$ and $24-38$ months $(\mathrm{T} 2=2560)$ following the standard's implementation. Smoking status, weekly frequency of physical activity and daily fruit and vegetable consumption 